Research Article

\title{
Study on Influencing Factors of Asphalt-Aggregate Stripping Mechanism
}

\author{
Fuyu Wang, ${ }^{1}$ Yan Li $\left(D,{ }^{2}\right.$ Liting Yu, ${ }^{2}$ and Weichen Pang ${ }^{1}$ \\ ${ }^{1}$ Transportation College of Jilin University, Changchun 130022, Jilin, China \\ ${ }^{2}$ School of Highway, Chang'an University, Xi'an 710064, Shaanxi, China \\ Correspondence should be addressed to Yan Li; liyan@chd.edu.cn
}

Received 21 December 2020; Revised 16 January 2021; Accepted 28 January 2021; Published 8 February 2021

Academic Editor: Pengfei Liu

Copyright (c) 2021 Fuyu Wang et al. This is an open access article distributed under the Creative Commons Attribution License, which permits unrestricted use, distribution, and reproduction in any medium, provided the original work is properly cited.

In order to study the stripping mechanism of asphalt aggregate comprehensively, the conditions of the stripping of asphalt aggregate are divided into two types, which are anhydrous environment and water environment. The stress generation and release of asphalt film under anhydrous environment and the differences in stripping mechanism of asphalt film under tensile and pressure stress were analyzed. The existence of water in the mixture and its harmfulness to stability were also described in this paper. Moreover, the transport behavior of water in asphalt was studied by the principles of electrochemical testing. The test results show that the diffusion rate of water in modified asphalt film is one half of that of base asphalt, so the blocking water ability of modified asphalt is better than that of matrix asphalt. Moreover, the condition of water spalling the asphalt-aggregate interface is characterized by a change in the mass of asphalt film before and after boiling. It can be concluded that the mass loss of asphalt film is minimal with limestone and modified asphalt, which shows that it has the best spalling resistance.

\section{Introduction}

Water damage of asphalt pavement can seriously reduce pavement performance $[1,2]$. With the increase of service life of asphalt pavement, asphalt in the mixture will also have different degrees of aging. When the aging is more serious, its ductility and plasticity become very poor $[3,4]$. Due to the intrusion of water, asphalt film will gradually peel off. In addition to external factors such as load and moisture, the resistance to water damage of asphalt pavement also depends on the water stability of the asphalt mixture [5-7].

Many mechanics models have been proposed to characterize the stripping mechanism of asphalt aggregate. Silvia et al. proposed the coupling micromechanical model of water damage of asphalt mixture, analyzed the damage caused by water diffusion in the mixture and the coupling effect of vehicle load on the mixture, determined the location and time of the damage, and provided a strong basis for the study of water damage [8]. Kim et al. proposed a model that can predict and evaluate the process of stripping in mixtures [9]. The microstructure, viscoelasticity, and crack tip properties of the mixture are considered in this model. Through the experimental observation data, the model was modified, making the model more authentic. Based on the surface energy theory, Zhang compared the free energy variation values of four typical asphalt-aggregate combination systems by calculating the surface energy parameters of different asphalts and aggregates [10]. Laurence applied physicochemical methods to analyze the interface stripping mechanism between asphalt and aggregates and proposed that improving the ratio of the aromatic fraction to colloid in asphalt was beneficial to the adhesion of the asphalt-aggregate interface, thus reducing the water sensitivity of the mixture [11]. Liu revealed the stripping mechanism of oxide skin under different stress states by studying the growth and thickening process of oxide skin in a supercritical boiler, which can play a reference role in the stripping of asphalt aggregate [12].

The study on the stripping mechanism of asphalt aggregate is inseparable from the study on adhesion. Most of the stripping mechanisms are analyzed using adhesion or stripping tests and by establishing the damage model of the 
mixture. However, the research only focuses on the stripping of asphalt aggregate by water, and there is less research on stripping in the absence of water. When water stripping is considered, most cases of adhesion are evaluated by the final stripping results, and the water damage process is not refined. In response to these problems, this paper analyzes the stripping of asphalt films under external force under waterless conditions. Water-immersion damage is divided into two stages: water invasion of asphalt films and water to asphalt-aggregate interface stripping.

\section{Materials and Methods}

Aggregate is limestone, basalt and granite. The performance indicators are shown in Table 1. Asphalt is 70\# matrix asphalt and SBS modified asphalt. The basic properties are shown in Table 2.

\section{Stripping Mechanism of Asphalt Film in Anhydrous Environment}

3.1. Generation of Load Stress and Temperature Stress. The action of vehicle load is one of the key factors affecting the pavement service life. The effect of vehicle load on the road can be divided into stopping state and running state. When the car is stopped, the force on the road surface is static pressure, mainly the vertical pressure from the tire to the road surface. In addition, the vehicle also exerts horizontal force, seismic force, and asphalt suction on the road $[13,14]$. The repeated action of these vehicle loads has an important effect on the stripping of asphalt film from the aggregate surface.

The asphalt film is also affected by temperature stress during the use of asphalt pavement. Asphalt aging leads to the increase of asphalt viscosity, smaller needle penetration, poor ductility, rheology, and so forth, which are manifested as "brittle" on the macro level and show as a solid state to a certain extent [15-17]. In the process of constant replacement of high and low temperature, asphalt swells and shrinks. Due to the difference of thermal expansion coefficient between the aged asphalt film and aggregate, thermal stress is generated in the asphalt film, which promotes the stripping of the asphalt film.

3.2. Stress Release of Asphalt Film. Through the above analysis, it is inevitable that the stress of asphalt film exists. When the stress of the asphalt film reaches a certain limit value, the asphalt film or aggregate needs to change to reduce the stress between the asphalt film and the aggregate. In theory, the release of the stress can be achieved by the destruction of the asphalt film and the plastic deformation of the asphalt film or the aggregate.

Firstly, combined with previous studies, the data suggest that the asphalt film of asphalt pavement aged seriously after being used for a long time and almost lost its deformation capacity $[18,19]$. Due to the nature of aggregate, the deformation space is very small under high and low temperature and repeated load. Therefore, it is impossible to consider the plastic deformation of aggregate. Under the condition of severe asphalt aging, the fracture and damage of asphalt film lead to stripping, which is the main cause of stress release of asphalt film.

3.3. Stripping of Asphalt Film in Anhydrous Environment. In the normal operation stage, the vehicle load produces various stress effects on the asphalt mixture. At the same time, the alternations of the ambient temperature of asphalt mixture cause the alternations of expansion and contraction of asphalt and aggregate. In general, the thermal expansion coefficient of asphalt film and aggregate is different. At this time, thermal stress will be generated inside the asphalt film, especially in areas with large temperature difference between day and night [20]. The better adhesion of asphalt to the aggregate surface depends on the comparison of the fracture strength of the asphalt-aggregate interface and the asphalt itself. If combined with the mentioned stress, when the stress of the asphalt film exceeds its fracture limit, it will peel off from the aggregate surface.

3.3.1. Stripping Mechanism under Tensile Stress. As shown in Figure 1, due to the varying degrees of asphalt film aging, the aging of a certain surface or intermediate parts is the most serious, or defects in the process of stress will produce stress concentration. Under the action of tensile stress, due to the weak strength of this part, when the tensile stress exceeds the tip limit stress, cracks will occur. With the alternating action of temperature stress and load stress, as well as the entry of external water and debris, the crack further expanded, resulting in penetration crack, until the stripping of the asphalt film.

3.3.2. Stripping Mechanism under Compressive Stress. As shown in Figure 2(a), when the aging site or defect site is located at the bottom of the asphalt film, the interface crack first grows from there under the action of tensile stress or compressive stress and then develops into the stripping of the asphalt film.

As shown in Figure 2(b), due to the lack of adhesion force at an interface, it is obviously less than the internal strength of the asphalt film. Under the action of compressive stress, the asphalt film at the surface will wrinkle. At this time, the top of the wrinkle is continuously thinned by stress, and the fracture stress limit is reduced. As a result, the asphalt film will break and fail.

As shown in Figure 2(c), when the strength of the asphalt-aggregate interface is less than the internal strength of the asphalt film but the difference is not obvious, the asphalt film will arch under the compressive stress and the tensile stress is biased towards the vault. At this time, the cracks in the asphalt film grow in a biased direction, and the stripping occurs when the critical stress value is reached.

As shown in Figure 2(d), when the strength of the asphalt-aggregate interface is much greater than the internal strength of the asphalt film, the asphalt film will peel off under large compressive stress. 
TABLE 1: The performance indicators of aggregate.

\begin{tabular}{|c|c|c|c|c|c|c|}
\hline \multirow{3}{*}{$\begin{array}{l}\text { Indicators } \\
\text { Crushing value (\%) }\end{array}$} & \multirow{2}{*}{\multicolumn{2}{|c|}{$\begin{array}{c}\text { Limestone } \\
\text { Standards results }\end{array}$}} & \multirow{2}{*}{\multicolumn{2}{|c|}{$\begin{array}{c}\text { Basalt } \\
\text { Standards results }\end{array}$}} & \multirow{2}{*}{\multicolumn{2}{|c|}{$\begin{array}{c}\text { Granite } \\
\text { Standards results }\end{array}$}} \\
\hline & & & & & & \\
\hline & $\ngtr 26$ & 15.0 & $\ngtr 26$ & 13 & $\ngtr 26$ & 13.5 \\
\hline Wearing value (\%) & $\ngtr 28$ & 21.0 & $\ngtr 28$ & 23 & $\ngtr 28$ & 12.9 \\
\hline Percentage of flat-elongated particle (\%) & $\ngtr 15$ & 1.8 & $\ngtr 15$ & 1.5 & $\ngtr 15$ & 10.5 \\
\hline Percentage of soft rock (\%) & $\ngtr 3$ & 0.5 & $\ngtr 3$ & 0.3 & $\ngtr 3$ & 0.6 \\
\hline Polished value (\%) & / & / & $\Varangle 42$ & 0.7 & $\nless 42$ & 44.1 \\
\hline
\end{tabular}

TABLE 2: The performance indicators of asphalt.

\begin{tabular}{lccc}
\hline Indicators & SK70\# & SBS-modified asphalt \\
\hline Penetration $\left(25^{\circ} \mathrm{C}, 100 \mathrm{~g}, 5 \mathrm{~g}\right)(0.1 \mathrm{~mm})$ & 69.0 & 56.0 \\
Ductility $\left(5 \mathrm{~cm} / \mathrm{min}, 5^{\circ} \mathrm{C}\right)(\mathrm{cm})$ & $>150$ & 30 \\
Softening point $(\mathrm{TR} \& \mathrm{~B})\left({ }^{\circ} \mathrm{C}\right)$ & 50 & 70 \\
Density $\left(\mathrm{g} / \mathrm{cm}^{2}\right)$ & & 0.987 & 0.997 \\
Solubility (trichloroethylene) $(\%)$ & Quality loss $(\%)$ & 99.8 & 99.85 \\
& Ductility $\left(5^{\circ} \mathrm{C}\right)(\mathrm{cm})$ & 0.33 & 0.01 \\
RTFOT $163^{\circ} \mathrm{C}, 85 \mathrm{~min}$ & Softening point $\left({ }^{\circ} \mathrm{C}\right)$ & 140 & 16 \\
& & 53 & 75 \\
\hline
\end{tabular}

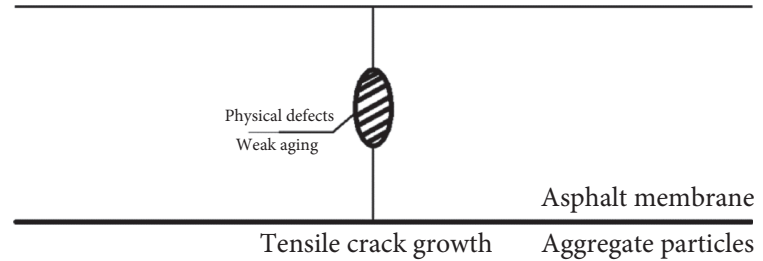

Figure 1: The weak state of the asphalt-aggregate interface.

From the above studies, it can be known that the ductility of asphalt deteriorates with aging. When the aging reaches a certain level, the alternating effects of tensile or compressive stress caused by traffic load and temperature stress on the asphalt, aggregate, and the interface between them will cause the interface to break and the stripping of the asphalt. But under tensile and compressive stress, there are some differences in the way the asphalt film peels off.

\section{Stripping Mechanism of Asphalt Film under Water Environment}

4.1. Destruction of Asphalt-Aggregate Interface by Water. The spalling of asphalt and aggregate in the mixture by water is divided into two stages: the first stage is the process of water infiltrating the asphalt and destroying the asphalt film; the second is the damage to the interface after the water invades the asphalt-aggregate interface. It is actually a continuation of the content of the previous section. The destructive effect of water on the asphalt-aggregate interface was studied by the water boiling test in the test specification $[21,22]$. In order to avoid the influence of human factors in the boiling method, this test combines the quality of the asphalt film before and after boiling to characterize the stripping of the asphalt.
4.1.1. Test Methods. First, pick out some particles larger than $13.2 \mathrm{~mm}, 24$ each of limestone, basalt, and granite. The aggregates are washed and dried and numbered one by one. Then, tied with thin iron wires and weighed and recorded as $m_{1}$, the asphalt is completely covered with aggregate, the test method is the same as the conventional boiling method, and the prepared particles are weighed and recorded as $m_{2}$. Then, the boiled test was started and three aggregates were taken out every $10 \mathrm{~s}$ within $1 \mathrm{~min}$ after the start, dried, and weighed. After $1 \mathrm{~min}$, the three aggregates are taken out every $1 \mathrm{~min}$, dried, and weighed until the boiling test is $3 \mathrm{~min}$; finally, the aggregate particles are taken out after boiling for $3 \mathrm{~min}$ to determine the adhesion level.

The calculation of the asphalt spalling rate $W_{b}$ is shown in

$$
W_{b}=\frac{m_{3}-m_{2}}{m_{2}-m_{1}}
$$

The main reason for the determination of the stripping of the asphalt within $1 \mathrm{~min}$ of the previous boiling test is to determine whether the water boiling method can be used to characterize the effect of water on the asphalt-aggregate interface.

4.1.2. Analysis of Test Results. Tables 3 and 4 are the results of boiling test.

From the above data, the stripping of the asphalt has occurred within the boiling time of about $10 \mathrm{~s}$ to $20 \mathrm{~s}$, but the amount of stripping is small, and the stripping rate increases rapidly later. Therefore, it can be considered as the time for water to invade the asphalt film under boiling conditions. At the same time, the intrusion time is very small compared with the test time of $3 \mathrm{~min}$ in the adhesion rating test of the boiling method, which can be ignored. Therefore, the influence of water on the interface between asphalt and aggregate can be approximated by boiling test. 


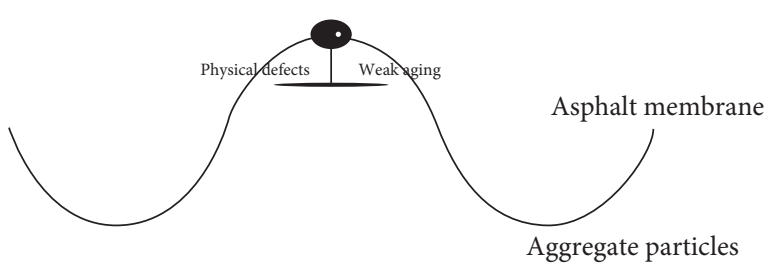

(a)

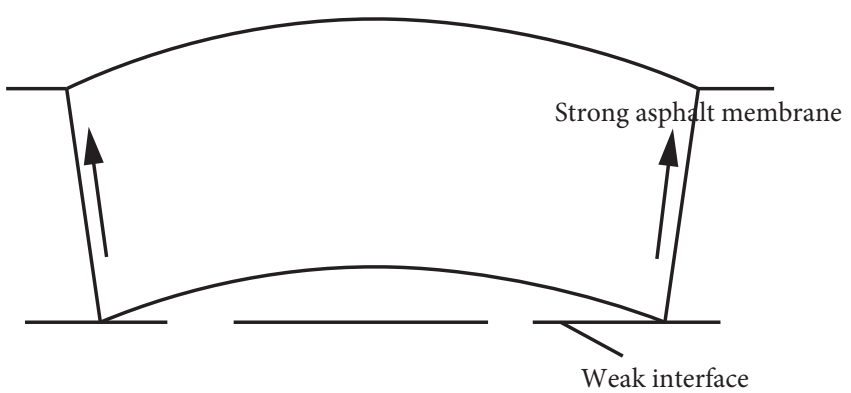

(c)

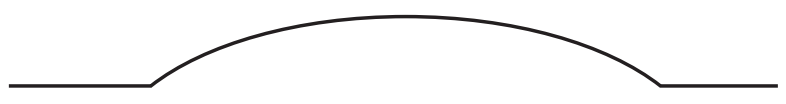

Strong asphalt membrane

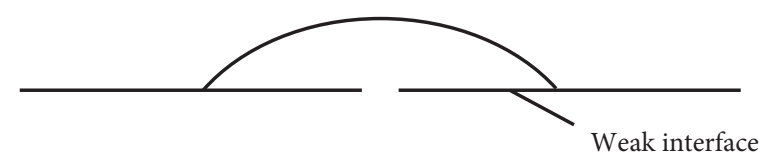

(b)

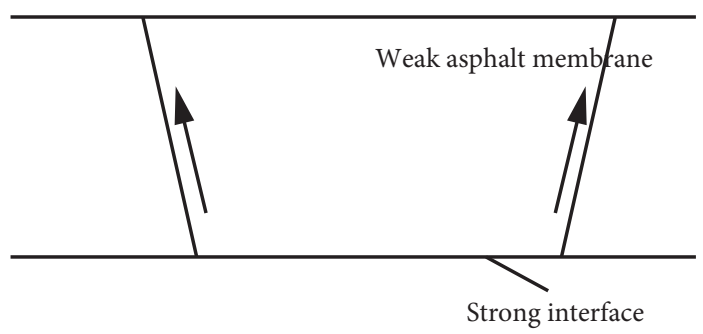

(d)

FIGURE 2: Stripping mechanism of asphalt film under compressive stress. (a) Interfacial crack growth. (b) Asphalt membrane wrinkling. (c) Crack biased growth. (d) Asphalt membrane striping.

TABLE 3: Stripping rate of matrix asphalt in boiling test $W_{b}(\%)$.

\begin{tabular}{lcccccccc}
\hline Testing time & $10(\mathrm{~s})$ & $20(\mathrm{~s})$ & $30(\mathrm{~s})$ & $40(\mathrm{~s})$ & $50(\mathrm{~s})$ & $1(\mathrm{~min})$ & $2(\mathrm{~min})$ & $3(\mathrm{~min})$ \\
\hline Limestone & 0.01 & 0.05 & 0.12 & 0.19 & 0.27 & 0.43 & 5.52 & 7.20 \\
Basalt & 0.01 & 0.06 & 0.15 & 0.20 & 0.42 & 1.28 & 5.99 & 9.12 \\
Granite & 0.01 & 0.11 & 0.34 & 1.16 & 2.44 & 3.56 & 10.22 \\
\hline
\end{tabular}

TABLE 4: Stripping rate of modified asphalt in boiling test $W_{b}(\%)$.

\begin{tabular}{lcccccccc}
\hline Testing time & $10(\mathrm{~s})$ & $20(\mathrm{~s})$ & $30(\mathrm{~s})$ & $40(\mathrm{~s})$ & $50(\mathrm{~s})$ & $1(\mathrm{~min})$ & $2(\mathrm{~min})$ & $3(\mathrm{~min})$ \\
\hline Limestone & 0.01 & 0.03 & 0.08 & 0.14 & 0.25 & 0.40 & 3.75 & 4.48 \\
Basalt & 0.01 & 0.04 & 0.13 & 0.18 & 0.37 & 1.09 & 4.33 \\
Granite & 0.01 & 0.07 & 0.22 & 0.81 & 1.94 & 2.32 & 9.34 \\
\hline
\end{tabular}

Table 5 shows the adhesion level of asphalt aggregate after 3 minutes of boiling.

It can be seen from the above table that the antistripping performance of limestone, basalt, and granite at the interface with asphalt is decreasing. At the same time, compared with matrix asphalt, modified asphalt has better interface antistripping performance. The analysis of the influence of water on the stripping of asphalt film in the presence of water shows that the antistripping properties of limestone, basalt, granite, matrix asphalt, and modified asphalt have good regularity.

4.2. Water Transport Behavior Based on Electrochemistry. Asphalt is the first to be damaged by water in the mixture, and the ability of asphalt to resist water immersion plays a significant role in the water stripping resistance of the
TABLE 5: Comparison of adhesion levels.

\begin{tabular}{lccc}
\hline Level of adhesion & Limestone & Basalt & Granite \\
\hline Matrix asphalt & 5 & 4 & 3 \\
Modified asphalt & 5 & 5 & 4 \\
\hline
\end{tabular}

mixture. There are many methods to study the transport behavior of water in asphalt, such as weight method [23], infrared spectroscopy-attenuated total reflection [24], and diffusion-through test [25]. Different from the above methods, this paper uses an electrochemical method to test the basic principle as follows.

Firstly, the asphalt film can be regarded as a parallel-plate capacitor with certain electrochemical properties, and its capacitance value can be calculated by the following equation: 


$$
C=\varepsilon \varepsilon_{0} \frac{S}{H},
$$

where $\varepsilon_{0}$ is the dielectric constant of vacuum $(8.85 \times 10-14 \mathrm{~F} /$ $\mathrm{cm}), \varepsilon$ is the dielectric constant of asphalt film, $S$ is the area of asphalt film acting as a capacitor plate, and $H$ is the thickness of asphalt film.

It is generally believed that asphalt has hydrophobicity, but after the asphalt is soaked in water for a long time, the water will gradually infiltrate into the asphalt, so with the change of time, the electrochemical properties of asphalt film will change. In formula (2), the main components of the dielectric constant of asphalt film are as follows:

$$
\varepsilon=\varepsilon_{s}^{\phi_{s}} \cdot \varepsilon_{w}^{\phi_{w}} \cdot \varepsilon_{a}^{\phi_{a}},
$$

where $\varepsilon$ is the dielectric constant, $\phi$ is the volume fraction of each component, and $s, w$, and $a$ represent the polymer body, water, and air in the asphalt film.

The specific reason is that the dielectric constant of water is about $80 \mathrm{~F} / \mathrm{cm}\left(20^{\circ} \mathrm{C}\right)$, which is much higher than the dielectric constant of asphalt $(2-6 \mathrm{~F} / \mathrm{cm})$. Therefore, the dielectric constant of asphalt film will increase after soaking in water, and the capacitance of asphalt film will increase. The diffusion of water in asphalt can be inferred from the relationship between the capacitance of asphalt film and soaking time.

4.2.1. Test Equipment and Sample Preparation. The test capacitance measuring equipment includes LCR digital bridge (as shown in Figure 3), graphite rod, airtight container ( $5 \mathrm{~cm}$ long, $3 \mathrm{~cm}$ wide), waterproof washer, aluminum plate (alloy hard aluminum), Vernier calipers, asphalt (matrix, modified asphalt), and water (electrolyte). The general schematic diagram of the test device is shown in Figure 4.

Put a piece of aluminum plate that is $15 \mathrm{~cm}$ long and $7 \mathrm{~cm}$ wide on the heater, then heat the asphalt to $160^{\circ} \mathrm{C}$, take a small amount of aluminum plate, and use a powder scraper to drag down the surface of the asphalt evenly coated on the aluminum plate surface, waiting for the asphalt and aluminum plate to cool to room temperature. Vernier calipers were used to measure the thickness of the asphalt film to $10 \mu \mathrm{m}$. Three parallel samples were prepared for each of the two asphalt samples to calculate the mean value.

4.2.2. Test Results and Analysis. According to the CM model of water transport behavior in general coatings proposed by $[26,27]$, which is used for water transport in asphalt films, the following expression can be obtained [28]:

$$
\frac{\lg C_{t}-\lg C_{0}}{\lg C_{\infty}-\lg C_{0}}=\frac{2}{H} \sqrt{\frac{D}{\pi}} \sqrt{t},
$$

where $C_{t}$ is the capacitance value of the asphalt film at time $t$, $C_{0}$ is the capacitance value of the asphalt film at $t=0, C_{\infty}$ is the capacitance value when the asphalt film is saturated with water, $D$ is the diffusion rate of water in the asphalt film, and $H$ is the thickness of the asphalt film.

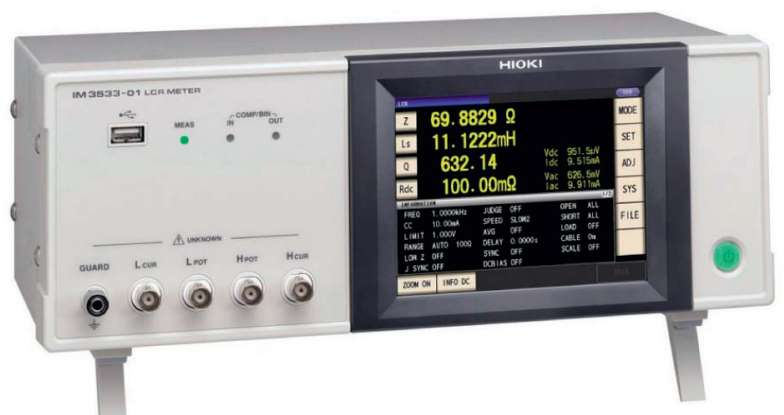

FIGURE 3: LCR digital bridge (IM3533-01).

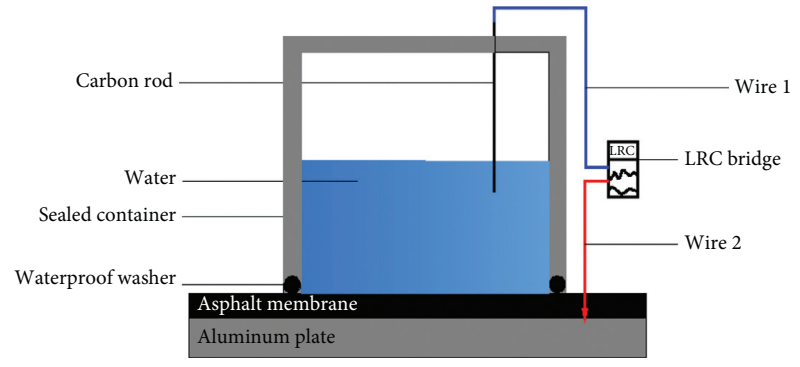

Figure 4: The general schematic diagram of the test device.

The above formula shows that there is a linear relationship between $\lg C_{t} \sim \sqrt{t}$ during soaking. Therefore, the diffusion coefficient of water in the asphalt can be obtained by calculating the slope of the linear law, and then the ability of the asphalt film to block water molecules can be judged. The change of asphalt film capacitance with time is shown in Table 6.

It can be seen from the above table that with the lengthening of soaking time, the capacitance of asphalt film gradually increases, but the capacitance of the modified asphalt film is significantly smaller than that of the matrix asphalt under the same soaking time, which means that the moisture content in the modified asphalt film is less, indicating that the water-resistance capacity of the modified asphalt is better than that of the matrix asphalt.

According to the data in the fitting Table 6, Figures 5 and 6 show the relationship between the capacitance of matrix asphalt film and modified asphalt film with soaking time.

The slope $K$ of the curve is shown in Table 7.

Since the slope of the curve and the diffusion rate have the following relationship, $K=2 \sqrt{D} / H \sqrt{\pi}$, we can get the following formula:

$$
D=\frac{H^{2} \pi}{4} k^{2} .
$$

The diffusion rate of water in different asphalt films is shown in Table 8 .

The comparison shows that the diffusion rate in the modified asphalt film is smaller than that of the matrix asphalt, and the ability of the modified asphalt to block water is better than that of the matrix asphalt. 
TABLE 6: The change of asphalt film capacitance with time.

\begin{tabular}{|c|c|c|c|c|c|c|}
\hline Test time & & $1(\mathrm{~h})$ & $12(\mathrm{~h})$ & $24(\mathrm{~h})$ & $120(\mathrm{~h})$ & $240(\mathrm{~h})$ \\
\hline \multirow{4}{*}{ Matrix asphalt $\left(\times 10^{-8} \mathrm{~F}\right)$} & Specimen 1 & 1.44 & 1.89 & 2.18 & 4.34 & 6.95 \\
\hline & Specimen 2 & 1.63 & 1.93 & 2.35 & 4.33 & 7.17 \\
\hline & Specimen 3 & 1.67 & 2.04 & 2.33 & 4.45 & 7.12 \\
\hline & Average & 1.58 & 1.95 & 2.29 & 4.37 & 7.08 \\
\hline \multirow{4}{*}{ Modified asphalt $\left(\times 10^{-8} \mathrm{~F}\right)$} & Specimen 1 & 0.96 & 1.22 & 1.24 & 1.98 & 2.25 \\
\hline & Specimen 2 & 0.91 & 1.10 & 1.16 & 1.83 & 2.20 \\
\hline & Specimen 3 & 0.86 & 1.03 & 1.30 & 2.15 & 2.24 \\
\hline & Average & 0.91 & 1.12 & 1.23 & 1.99 & 2.23 \\
\hline
\end{tabular}



FIGURE 5: The relationship between the capacitance of matrix asphalt film and soaking time.

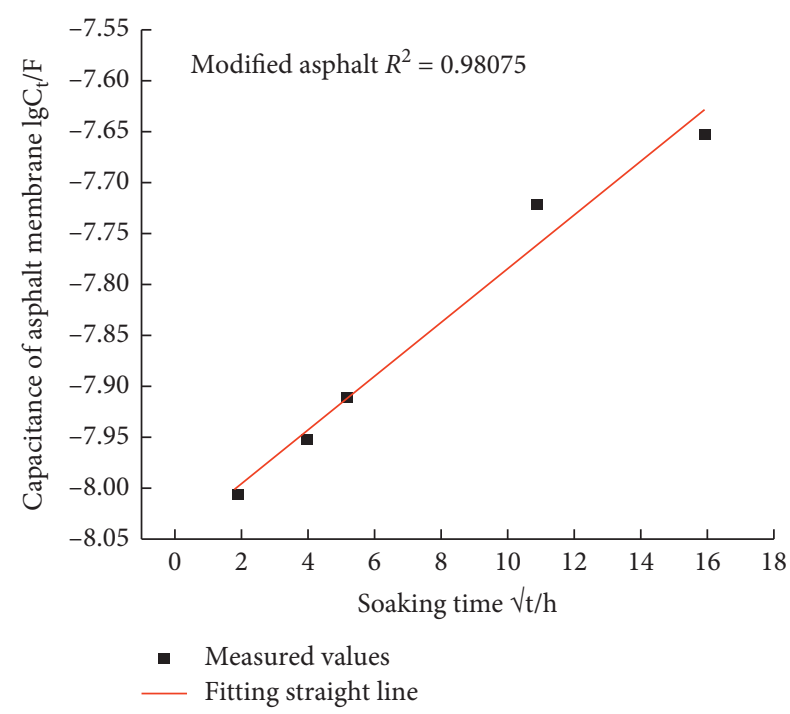

FIGURE 6: The relationship between the capacitance of modified asphalt film and soaking time.

TABle 7: Slope $K$ of curve.

\begin{tabular}{lcc}
\hline Asphalt & Matrix asphalt & Modified asphalt \\
\hline Slope $K$ & 0.0462 & 0.0336 \\
\hline
\end{tabular}

TABle 8: The diffusion rate of water in different asphalt.

\begin{tabular}{lcc}
\hline Asphalt & Matrix asphalt & Modified asphalt \\
\hline Diffusion rate $\left(\mathrm{cm}^{2} \cdot \mathrm{s}^{-1}\right)$ & $4.63 \times 10^{-13}$ & $2.46 \times 10^{-13}$ \\
\hline
\end{tabular}

\section{Conclusions}

(1) This paper mainly discusses the mechanism of asphalt-aggregate stripping, which is divided into two parts: the stripping mechanism of asphalt-aggregate in anhydrous environment and the stripping effect of water on the asphalt under water environment. At the same time, the measures to improve the antistripping property of asphalt aggregate are analyzed. The main conclusions are as follows.

(2) From a mechanical point of view, it is possible to intuitively analyze the stripping mechanism of asphalt in the absence of water, and it can be known that the mechanism of asphalt stripping may be different under tensile or compressive stress.

(3) The stripping of the asphalt film at different time periods was analyzed by the boiling method. It is considered that the time for water to invade the asphalt film is shorter than the adhesion level evaluation time under boiling conditions. So, it is negligible and the effect of water on the asphaltaggregate interface can be approximated by the boiling method. The antistripping performance of limestone, basalt, and granite with matrix asphalt and modified asphalt has good regularity.

(4) The electrochemical method was used to study the change of the asphalt film capacitance during the immersion of asphalt in water. The capacitance of the asphalt film increases with the immersion time, and the logarithm of the capacitance value increases linearly with the square root of the immersion time, indicating that the asphalt's ability to block water gradually decreases. In addition, the capacitance of the modified asphalt film is significantly smaller than that of the matrix asphalt under the same soaking time. Therefore, the modified asphalt has better water resistance than matrix asphalt.

(5) Analyzing the test data, we get the diffusion rate of water in different asphalt films. The diffusion rate of water in the modified asphalt film is smaller than that in the matrix asphalt, and the ability of the modified 
asphalt to block water is better than that of the matrix asphalt.

\section{Data Availability}

The data used to support the findings of this study are available from the corresponding author upon request.

\section{Conflicts of Interest}

The authors declare no conflicts of interest.

\section{Acknowledgments}

This work was supported by National Science Foundation of China (No. 51978068), National Key R\&D Program of China (No. 2018YFE0103800), China Postdoctoral Science Foundation (No. 2017M620434), Shaanxi Postdoctoral Grant Program (No. 2017BSHYDZZ17), and the Special Fund for Basic Scientific Research of Central College of Chang'an University (No. 310821173501). The authors gratefully acknowledge their financial support.

\section{References}

[1] Z. G. Zhou and Y. Li, "Dynamic response analysis of asphalt pavement structures under different seepage patterns," China Journal of Highway and Transport, vol. 3, pp. 13-24, 2019.

[2] X. L. Peng, "Analysis and treatment of water seepage disease of asphalt pavement," Highway Engineering, vol. 4, pp. 182$185,2014$.

[3] Y. N. Li, Y. Lyv, L. Fan, and Y. Zhang, "Effects of cement and emulsified asphalt on properties of mastics and $100 \%$ cold recycled asphalt mixtures," Materials, vol. 12, no. 5, p. 754, 2019.

[4] X. D. Wang, P. Wang, and S. Michel, "Research and analysis of asphalt pavement water damage," China Highway, vol. 22, pp. 74-76, 201.

[5] W. Wang, L. B. Wang, L. Wang, H. Xiong, and R. Luo, "A review and perspective for research on moisture damage in asphalt pavement induced by dynamic pore water pressure," Construction and Building Materials, vol. 204, pp. 631-642, 2019.

[6] S. S. Yang, "Study on damage of asphalt concrete pavement under different flood conditions," Transport World, vol. 27, pp. 42-43, 2017.

[7] R. Luo and T. T. Huang, "Moisture movement in asphalt mixture," Journal of Chongqing Jiaotong University (Natural Science), vol. S1, pp. 49-60, 2016.

[8] C. Silvia, E. Masad, A. Bhasin, and D. Little, "Coupled micromechanical model of moisture-induced damage in asphalt mixtures," Journal of Materials in Civil Engineering, vol. 22, no. 4, pp. 380-388, 2010.

[9] Y.-R. Kim, F. T. Sacramento Aragão, D. Allen, and D. Little, "Damage modeling of bituminous mixtures considering mixture microstructure, viscoelasticity, and cohesive zone fracture," Canadian Journal of Civil Engineering, vol. 37, pp. 1125-1136, 2010.

[10] P. Zhang and L. Z. Yang, "Analysis of asphalt and aggregate adhesion and stripping mechanism based on surface energy theory," Highway Engineering, vol. 38, no. 4, pp. 187-190, 2013.
[11] B. Laurence, B. Estelle, and S. Michel, "Physicochemical characterisations of the bitumen-aggregate interface to get a better understanding of stripping phenomena," Road Materials and Pavement Design, vol. 14, no. 2, pp. 384-403, 2013.

[12] D. C. Liu, Study on Stripping Mechanism and Key ExplosionProof Technology of Supercritical Power Plant Boiler, South China University of Technology, Guangzhou, China, 2012.

[13] L. L. Li and X. M. Huang, "Permanent deformation of asphalt pavement under horizontal moving load," Journal of South China University of Technology (Natural Science Edition), vol. 39, no. 3, pp. 125-129, 2011.

[14] Y. H. Pi and Y. Li, "Wetting model of asphalt on the aggregate surface and its effect factors," Advances in Materials Science and Engineering, vol. 2019, Article ID 4126464, 7 pages, 2019.

[15] J. L. Song and L. He, "RTFOT microscopic aging mechanism of SBS modified asphalt," Journal of Highway Communication Technology, vol. 2, pp. 1-7, 2020.

[16] Y. Y. Wang and D. M. Yue, "The research based on the surface energy theory to evaluate asphalt/stone interface bonding performance," Chinese and Foreign Road, vol. 33, no. 3, pp. 247-250, 2013.

[17] A. Kilger, D. Swiertz, D. Swiertz, and H. U. Bahia, "Long-term aging performance analysis of oil modified asphalt binders," Transportation Research Record: Journal of the Transportation Research Board, vol. 2673, no. 12, pp. 404-412, 2019.

[18] J. Jin and Y. C. Gao, "Rheological and adhesion properties of nano-organic palygorskite and linear SBS on the composite modified asphalt," Powder Technology, vol. 377, pp. 212-221, 2021.

[19] J. Jin, Y. C. Gao, Y. Wu et al., "Performance evaluation of surface-organic grafting on the palygorskite nanofiber for the modification of asphalt," Construction and Building Materials, vol. 268, Article ID 121072, 2021.

[20] A. Bhasin and D. N. Little, "Application of microcalorimeter to characterize adhesion between asphalt binders and aggregates," Journal of Materials in Civil Engineering, vol. 21, no. 6, pp. 235-243, 2009.

[21] A. R. Copeland, Influence of Moisture on Bond Strength of Asphalt-Aggregate Systems, Vanderbilt University, Nashville, TN, USA, 2007.

[22] G. H. Lai, "The influence of asphalt chemical composition on pavement water damage," The Chinese and Foreign Road, vol. 24, no. 4, pp. 52-53, 2004.

[23] Q. Yuan and Y.-P. Zhao, "Multiscale dynamic wetting of a droplet on a lyophilic pillar-arrayed surface," Journal of Fluid Mechanics, vol. 716, pp. 171-188, 2013.

[24] T. Nguyen, E. Byrd, and D. Bentz, SHRP-92-611: Development of a Technique for In-Situ Measurement of Water at the Asphalt/model Siliceous Aggregate Interface, Strategic Highway Research Peogram, Washington, DC, USA, 1992.

[25] A. Bhasin and D. Little, Material Properties to Characterize and Model Moisture Damage in Asphalt mixes. 2nd International Workshop on Moisture Induced Damage of Asphalt Mixes, Texas A\&M University, Lubbock, TX, USA, 2007.

[26] B. Gwinnerb, J. Sercombea, and C. Tiffreauc, "Modelling of bituminized radioactive waste leaching. Part II: experimental validation," Journal of Nuclear Materials, vol. 349, no. 1-2, pp. 107-118, 2006.

[27] L. D. Rosa, T. Monelta, D. B. Mitton, and F. Bellucci, "Monitoring degradation of single and multilayer organic coatings," Journal of The Electrochemical Society, vol. 145, no. 11, pp. 3830-3838, 1998.

[28] J. M. Hu and J. Q. Zhang, "Water transport in organic coatings: fick diffusion process," Journal of Chinese Corrosion and Protection, vol. 22, no. 5, pp. 311-315, 2002. 